\title{
Single-stage Endovascular Treatment of a Penetrating Aortic Ulcer with a Concomitant "Isolated" Iliac Aneurysm
}

\author{
Haidi Hu, MD, PhD ${ }^{1,2^{*}}$, Jianming Guo, MD², Hualong Bai, MD, PhD ${ }^{2}$, Alan Dardik, MD, PhD 2 \\ 1 Department of Vascular and Thyroid Surgery, The First Affiliated Hospital, China Medical University, Shenyang 110001, China \\ ${ }^{2}$ Department of Surgery and Vascular Biology and Therapeutics Program, Yale University School of Medicine, New Haven, Connecticut, USA
}

\begin{abstract}
Penetrating aortic ulcer (PAU) is an acute aortic syndrome that can proceed to life-threatening aortic dissection or even aortic rupture. Isolated iliac aneurysms are relatively rare and often asymptomatic due to their deep pelvic location but are frequently associated with high mortality with rupture. We report a case of a 68-year-old man with a symptomatic penetrating ulcer in the descending aorta and an asymptomatic right iliac aneurysm involving the common and internal iliac arteries. The patient was successfully treated by endovascular repair in a single-stage manner using stent grafts in the descending aorta and right common iliac artery after coil embolization of the right internal iliac artery. Follow-up imaging showed complete resolution of the PAU and exclusion of the right iliac aneurysm without endoleak. Aggressive endovascular treatment for a symptomatic PAU with an asymptomatic isolated iliac aneurysm is feasible and allows complete treatment of vascular pathology at a single time.

Copyright @ 2017 Science International Corp.
\end{abstract}

\section{Key Words:}

Penetrating aortic ulcer • Iliac aneurysm • Endovascular

\section{Introduction}

Penetrating aortic ulcers (PAUs) are aortic atherosclerotic lesions that ulcerate through the internal elastic lamina into the media, allowing hematoma

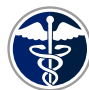

Fax +1 2037853552

E-Mail: aorta@scienceinternational.org

http://aorta.scienceinternational.org (c) 2017 AORTA

Published by Science International Corp. ISSN 2325-4637

Accessible online at: http://aorta.scienceinternational.org formation in the media [1]. PAU is one of three types of acute aortic syndrome that accounts for $2-11 \%$ of all acute aortic syndromes [2]. Elefteriades' group recognized the aggressive nature of PAUs and differentiated their early behavior from that of classic type $A$ and $B$ dissections, showing that the rupture rate of symptomatic PAUs is as high as 38\% [3].

Isolated internal iliac aneurysms (IIAs), in absence of a concomitant abdominal aortic aneurysm, are unusual. Many IIAs are asymptomatic and are found incidentally, as their deep location in the pelvis precludes routine detection; however, patients with IIA frequently present with multiple aneurysms (43-67\%) [4]. The incidence of IIA rupture in Western and Asian patients is approximately $30 \%$ [4]; however, IIA rupture is associated with high mortality (30-50\%) [5], and the threshold for elective repair is generally considered to be $30 \mathrm{~mm}$ in maximal transverse diameter $[4,5]$.

Here, we report a case of symptomatic PAU associated with an asymptomatic right "isolated" IIA that was diagnosed incidentally during work-up for the PAU. Both the PAU and right IIA were successfully treated using a single-stage endovascular approach.

\section{Case Presentation}

A 68-year-old Chinese man with a history of smoking (45 years) and hypertension was admitted 
with acute severe chest and back pain. Electrocardiography showed nonspecific ST-T changes and normal ventricular function without pericardial effusion. His physical examination was unremarkable other than an elevated blood pressure of 185/106 $\mathrm{mmHg}$; laboratory tests showed normal troponin levels, and D-dimer was $510 \mathrm{ng} / \mathrm{ml}$ (normal range $<500 \mathrm{ng} / \mathrm{ml}$ ). The patient was suspected to suffer from an acute aortic syndrome and was treated with $\beta$-blockade and morphine. Three-dimensional computed tomography angiography showed a proximal descending penetrating aortic ulcer with associated intramural hematoma (Figure 1A, 1B, and 1C); there was also an aneurysm of the right common iliac artery (maximum diameter $36 \mathrm{~mm}$ ) involving the origin of the right IIA (Figure 2A). There were no other aneurysms.

After 4 days of medical treatment, his systolic blood pressure was no longer elevated, but he experienced only partial relief of chest pain; accordingly, repair of the symptomatic PAU and right IIA (> $30 \mathrm{~mm}$ ) was planned using a single-stage endovascular ap-
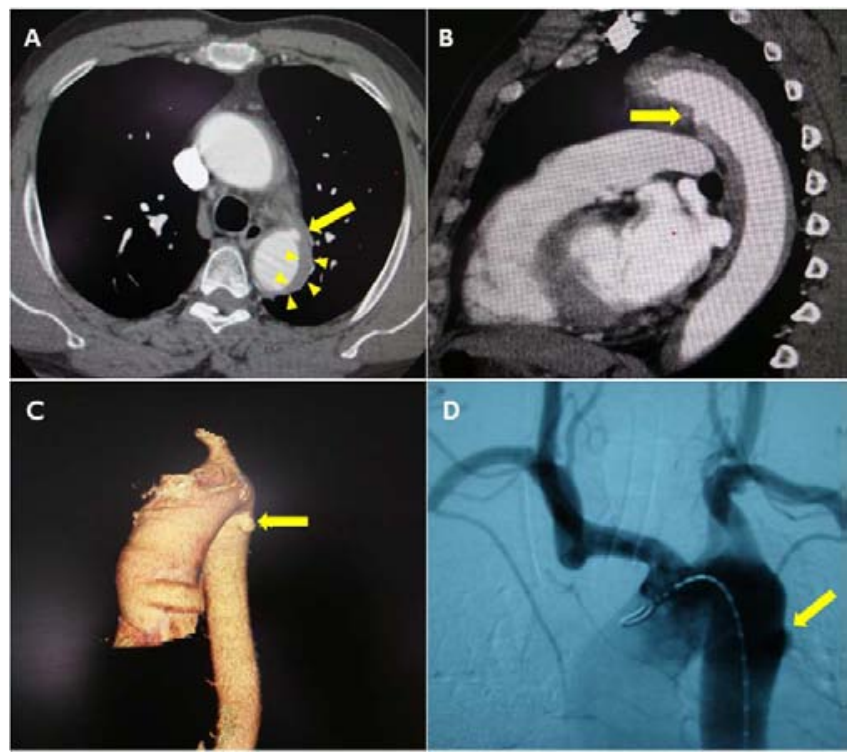

Figure 1. Computed tomography angiogram with contrast showing a penetrating aortic ulcer (PAU) (yellow arrow) with intramural hematoma (yellow solid triangles) in the axial plane (Panel A) and the PAU in the sagittal plane (Panel B). Panel $C$. Three-dimensional reconstruction demonstrating the PAU. Panel D. Intraprocedural angiogram demonstrating the PAU. proach. Under general anesthesia, the bilateral common femoral arteries were exposed; a 6-F sheath was placed in the left femoral artery, demonstrating the PAU (Figure 1D) and right IIA (Figure 2B). An 8-F sheath was used to place a Lunderquist extra-stiff guidewire (145 cm, Cook Medical, Bloomington, Indiana, USA) and catheter into the ascending aorta. The PAU was covered with a stent graft (diameter $36 \mathrm{~mm}$; length $150 \mathrm{~mm}$; Endurant, Medtronic Inc., Minneapolis, Minnesota, USA) starting immediately distal to the origin of the left subclavian artery; intraoperative angiography demonstrated no endoleak (Figure 3A). A 0.035" guidewire (TERUMO, Fujinomiya, Japan) was used to access the right IIA from the left femoral artery, and coil embolization was performed using two coils (diameter $15 \mathrm{~mm}$, MWCE-

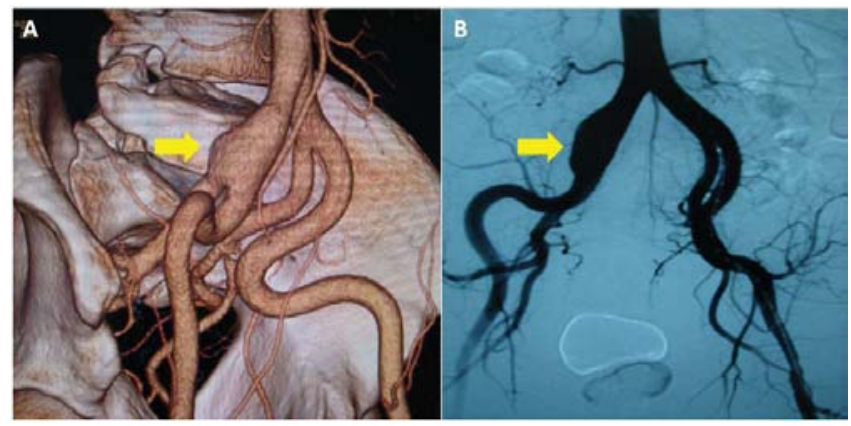

Figure 2. Panel A. Three-dimensional computed tomography angiogram demonstrating a right iliac aneurysm (yellow arrow) involving the right common iliac artery and the origin of the right internal iliac artery. Panel B. Intraprocedural angiogram identifying the right iliac aneurysm (yellow arrow).

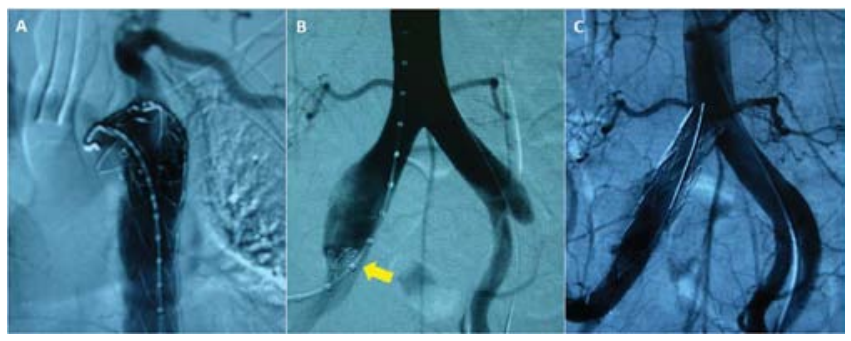

Figure 3. Panel $A$. Intraprocedural angiogram showing thoracic aortic stent-graft placement to treat the PAU. Panel $B$. Intraprocedural angiogram showing coil embolization of the right internal iliac artery (yellow arrow showing coils). Panel C. Intraprocedural angiogram showing stent-graft placement in the right common iliac artery and external iliac artery. 
35-8-15, Cook Medical) to exclude the IIA (Figure 3B). The IIA was covered with a stent graft (diameter $16 \mathrm{~mm}$, length $120 \mathrm{~mm}$, Endurant, Medtronic Inc.) placed from the right common iliac artery into the right external iliac artery. Completion angiography demonstrated no endoleak with good flow to the lower extremities (Figure $3 \mathrm{C}$ ). The operation time was $1.5 \mathrm{~h}$. The patient's chest pain was completely relieved, and he recovered well. He was discharged on postoperative day 7 .

Six months after discharge, computed tomography angiography showed good patency of both stent grafts without endoleak; there was no buttock claudication.

\section{Discussion}

PAUs frequently present as an acute aortic syndrome, with risk of intramural hematoma, pseudoaneurysm, rupture, or dissection [2]. PAUs often occur in elderly patients with extensive comorbidities, severe atherosclerosis, and a high incidence of abdominal aortic aneurysms $(42.1 \%)[3,6]$. Elefteriades' group showed that symptomatic PAUs must be treated emergently, as the PAU reaches the adventitia and rupture is expected $[3,7,8]$; the rupture rate of symptomatic PAUs is as high as $38 \%$ [3]. As with acute aortic dissection, PAU is classified according to the aortic site affected; type A PAU involves the ascending aorta, and type $B$ involves the descending thoracic aorta [9]. Type B PAU progression, persistent pain despite medical therapy, increasing pleural effusion, and coexistence of intramural hematoma are indications for repair $[8,9]$. In this case, the patient had persistent chest pain despite $\beta$-blockade and pain treatment as well as an intramural hematoma, mandating treatment to prevent rupture. As type B PAUs are frequently localized, open surgical repair shows excellent results $[3,8]$ and is considered the gold standard treatment. However, endovascular repair offers a less invasive approach in high-risk patients, showing good perioperative results with low 30-day mortality (4.8-7\%) [10].

IIAs are frequently asymptomatic and not easily detected due to their deep pelvic location; accordingly, they are frequently repaired electively. In this case, the IIA was above established treatment thresholds [4, 5]. Cambria et al. reported a series of 18 patients with spontaneous aortic dissection in the presence of coexistent or previously repaired aneurysms and showed that concomitant aortic pathologies increase the risk of aortic rupture in both proximal and distal aortic segments [11]. Chaer et al. reported a more contemporary series of synchronous and metachronous thoracic aneurysms in patients with abdominal aortic aneurysms and confirmed the high incidence of rupture with associated mortality in both abdominal and thoracic locations [12]. We believe that predisposing factors for acute aortic syndromes and degenerative aneurysms may overlap, increasing the risk of concomitant presenting entities. Accordingly, as the iliac artery is a first-order aortic branch, the rupture risk of the IIA in our patient was likely higher than that of an IIA without a thoracic aortic lesion, leading us to treat both the PAU and IIA in single-stage manner. Over the past decade, endovascular repair for IIAs has been established to be safe and effective in patients with appropriate anatomy, especially in the common iliac artery [5]. The different locations of the two entities in this patient (i.e., chest and pelvis) suggests that an endovascular approach may be preferable to the surgical trauma of two open procedures; in addition, this patient's left IIA was patent, minimizing the risk of pelvic ischemia and buttock claudication after coil embolization of the right IIA.

In summary, a symptomatic PAU associated with an asymptomatic IIA are synchronous aortoiliac lesions associated with a high risk of rupture of either lesion but can be treated in a single-stage manner using an endovascular approach. Despite lack of endoleak, continued surveillance is important, although the frequency of surveillance is not well established [10, 13]. In addition, patients with IIA frequently develop multiple aneurysms, suggesting that surveillance and screening remains a life-long concern. 


\section{Conflict of Interest}

\section{Comment on this Article or Ask a Question}

The authors have no conflict of interest relevant to this publication.

\section{References}

1. Stanson AW, Kazmier FJ, Hollier LH, Edwards WD, Pairolero PC, Sheedy PF, et al. Penetrating atherosclerotic ulcers of the thoracic aorta: natural history and clinicopathologic correlations. Ann Vasc Surg. 1986;1:15-23. DOI: 10.1016/S08905096(06)60697-3

2. Lansman SL, Saunders PC, Malekan R, Spielvogel D. Acute aortic syndrome. J Thorac Cardiovas Surg. 2010;140:S92-S97. DOI: 10.1016/j.jtcvs.2010.07.062

3. Tittle SL, Lynch RJ, Cole PE, Singh HS, Rizzo JA, Kopf GS, et al. Midterm follow-up of penetrating ulcer and intramural hematoma of the aorta. J Thorac Cardiovas Surg. 2002;123:1051-1059. DOI: 10.1067/ mtc.2002.121681

4. Hu H, Takano T, Guntani A, Onohara T, Furuyama $T$, Inoguchi $H$, et al. Treatment of solitary iliac aneurysms: clinical review of 28 cases. Surg Today. 2008;38:232-236. DOI: 10.1007/s00595-007-3598-1

5. Sandhu RS, Pipinos, II. Isolated iliac artery aneurysms. Semin Vasc Surg. 2005;18:209-215. DOI: 10.1053/j.semvascsurg.2005.09.007

6. Coady MA, Rizzo JA, Elefteriades JA. Pathologic variants of thoracic aortic dissections. Penetrating atherosclerotic ulcers and intramural hematomas. Cardiol Clin. 1999;17:637-657. DOI: 10.1016/ S0733-8651(05)70106-5

7. Nathan DP, Boonn W, Lai E, Wang GJ, Desai $\mathrm{N}$, Woo EY, et al. Presentation, complications, and natural history of penetrating atherosclerotic ulcer disease. JVasc Surg. 2012;55:10-15. DOI: 10.1016/j.jvs.2011.08.005

8. Chou AS, Ziganshin BA, Charilaou P, Tranquilli $M$, Rizzo JA, Elefteriades JA. Longterm behavior of aortic intramural hematomas and penetrating ulcers. J Thorac Cardiovas Surg. 2016;151:361-373. DOI: 10.1016/j.jtcvs.2015.09.012

9. Evangelista A, Czerny M, Nienaber C, Schepens M, Rousseau H, Cao P, et al. Interdisciplinary expert consensus on management of type B intramural haematoma and penetrating aortic ulcer. Eur J Cardiothorac Surg. 2015;47:209-217. DOI: 10.1093/ejcts/ ezu386

10. D'Annoville $T$, Ozdemir BA, Alric $P$, Marty-Ane CH, Canaud L. Thoracic endovascular aortic repair for penetrating aortic ulcer: literature review. Ann Thorac Surg. 2016;101:2272-2278. DOI: 10.1016/j.athoracsur.2015.12.036

11. Cambria RP, Brewster DC, Moncure AC, Steinberg FL, Abbott WM. Spontaneous aortic dissection in the presence of coexistent or previously repaired atherosclerotic aortic aneurysm. Ann Surg. 1988;208: 619-624. PMID: 3190289

12. Chaer RA, Vasoncelos R, Marone LK, AlKhoury G, Rhee RY, Cho JS, et al. Synchronous and metachronous thoracic aneurysms in patients with abdominal aortic aneurysms. J Vasc Surg. 2012;56:1261-1265. DOI: 10.1016/j. jvs.2010.06.037

13. Patel NV, Long GW, Cheema ZF, Rimar K, Brown OW, Shanley CJ. Open vs. endovascular repair of isolated iliac artery aneurysms: a 12-year experience. J Vasc Surg. 2009;49:1147-1153. DOI: 10.1016/j. jvs.2008.11.101

Cite this article as: $\mathrm{Hu} \mathrm{H}$, Guo J, Bai $\mathrm{H}$, Dardik A. Single-stage Endovascular Treatment of a Penetrating Aortic Ulcer with a Concomitant "Isolated" Iliac Aneurysm. AORTA (Stamford). 2017;5(6):177-180. DOI: https://doi. org/10.12945/j.aorta.2017.17.040 